\title{
Anticholinesterase activity of selected phenolic acids and flavonoids - interaction testing in model solutions
}

\author{
Dominik Szwajgier ${ }^{1}$ \\ ' Department of Biotechnology, Human Nutrition and Food Commodity Science, University of Life Sciences, Lublin, Poland \\ Szwajgier D. Anticholinesterase activity of selected phenolic acids and flavonoids: interaction testing in model solutions. Ann Agric Environ \\ Med. 2015; 22(4): 690-694. doi: 10.5604/12321966.1185777
}

\begin{abstract}
Introduction. Alzheimer's disease is a progressively developing neurodegenerative disorder of the central nervous system. The only present treatment of this disease is the use of acetyl- and butyrylcholinesterase inhibitors. Previously, the neuroprotection of phenolic acids and flavonoids in the brain has been indicated.

Materials and method. This study measured anticholinesterase activities of 9 phenolic acids and 6 flavonoids, singly or in combination. The synergy/antagonism/zero interaction between compounds was evaluated taking into consideration the statistical significance. Ellman's modified spectrophotometric method was used with the simultaneous measurement of the false-positive effect of compounds.

Results. The anti-acetylcholinesterase activity of phenolic acids was as follows: homogentisic acid > 4-hydroxyphenylpyruvic acid $>$ nordihydroguaiaretic acid $>$ rosmarinic acid $>$ caffeic acid $>$ gallic acid $=$ chlorogenic acid $>$ homovanillic acid $>$ sinapic acid. p-Hydroxyphenylpyruvic, caffeic, chlorogenic, gentisic, homogentisic, nordihydroguaiaretic and rosmarinic acids in pairs exhibited, in most cases, a lower inhibitory activity (at p $>0.05$ ), than the sum of the activities of single compounds. Also, phenolic acids in pairs with flavonoids (cyanidin, delphinidin, kaempferol, myricetin, phloridzin, pelargonidin or quercetin) presented, in most cases, a lower inhibitory activity than could be calculated for both compounds singly (at p $>0.05$ ). Only in the case of a few samples was the inhibitory activity of two compounds higher than the sum of inhibitions exerted by the same compounds tested singly (either at $p>0.05$ or $p<0.05$ ). The lack of synergy of pairs of inhibitors suggests one small binding site, making impossible to accommodate both inhibitors adjacent to one another.
\end{abstract}

\section{Key words}

Acetylcholinesterase, Alzheimer's disease, butyrylcholinesterase, phenolic acid, flavonoid

\section{Abbreviations}

AD, Alzheimer's disease; AChE, acetylcholinesterase; BChE, butyrylcholinesterase; 4-OH-PP, 4-hydroxyphenylpyruvic acid; CA, caffeic acid; CHA, chlorogenic acid; GA, gentisic acid; HGA, homogentisic acid; HVA, homovanillic acid; NDGA, nordihydroguaiaretic acid; RA, rosmarinic acid; SA, salicylic acid; KAE, kaempferol; PEL, pelargonidin; QUE, quercetin; PHL, phloridzin; DEL, delphinidin; CYA, cyanidin; MYR, myricetin; ATChI, acetylthiocholine iodide; BTCh, S-butyrylthiocholine chloride; DTNB, 5,5'-dithiobis-2-nitrobenzoic acid.

\section{INTRODUCTION}

The neuroprotection of phenolic acids has been previously repeatedly highlighted, e.g. of ferulic acid in the central nervous system of experimental animals [1]. Ferulic acid, p-coumaric acid, 4-hydroxybenzoic acid and sinapic acid are efficient in vitro acetylcholinesterase (AChE) and butyrylcholinesterase (BChE) inhibitors [2]. Sinapic acid and ferulic acid participate in the regulation of the acetylcholinesignalling system in experimental animals [3]. Amyloid- $\beta$ plaque deposition is significantly decreased in brains of mice fed nordihydroguaiaretic (NDGA) and rosmarinic acid (RA). Treatment with RA, curcumin and myricetin causes an increase in the content of soluble $\beta$-amyloid [4].

Previously, flavonoids had been identified as effective antioxidants in the brain [5]. Anthocyanins pelargonidin (PEL), delphinidin (DEL) and cyanidin (CYA), flavones

Address for correspondence: Dominik Szwajgier, Department of Biotechnology, Human Nutrition and Food Commodity Science, University of Life Sciences, Skromna 8, 20-704 Lublin, Poland.

E-mail: dszwajgier@hotmail.com

Received: 09 September 2013; accepted: 06 December 2013 apigenin and luteolin, flavonols quercetin (QUE), kaempferol (KAE) and myricetin (MYR), dihydrochalcone phloridzin (PHL) and prenylated chalcone xanthohumol are the most efficient in vitro inhibitors of $\mathrm{AChE}$ and/or BChE in a study testing 24 polyphenols. The lowest inhibitory activity is exerted by flavan-3-ols [6]. Flavonoids inhibit the formation and extension of amyloid- $\beta(1-40)$ or $(1-42)$ fibrils (in decreasing order: $\mathrm{MYR}=$ morin $=\mathrm{QUE}>\mathrm{KAE}>(+)$-catechin $=(-)$-epicatechin [7]. Also, flavonoids effectively destabilize preformed $\beta$-amyloid fibrils in a dose-dependent manner $[7,8]$. MYR decreases the toxicity of $\beta$-amyloid fibrils [7]. Genistein and daidzein increases AChE activity in rat neuronal cells PC12 [9]. (-)-Epigallocatechin gallate, hydroxytyrosol, resveratrol and tyrosol exhibit a cytoprotective effect on neuroblastoma IMR-32 and lymphoma U937 cell lines via an increase in the resistance of cellular DNA to oxidative damage [10]. (-)-Epigallocatechin gallate reduces free radical and malondialdehyde content, increases caspase activity after ex vivo pretreatment with $\beta$-amyloid, and elevates the percentage survival rate of hippocampal neuronal cells from Sprague-Dawley rat embryos previously incubated with $\beta$-amyloid [11]. CYA, KAE, epicatechin, rutin, naringenin, 
taxifolin and luteolin exert a neuroprotective role towards the primary cells of mouse striatal neurons in the presence of oxidized low-density lipoproteins [12].

Alzheimer's disease (AD) is a severe disease of the central nervous system involving the loss of cholinergic neurons [13], an imbalance of the AChE and BChE activity and the deposition of intra- and extracellular $\beta$-amyloid in the brain tissue [14]. The present therapeutics are based on the inhibition of AChE and BChE activity in the brain leading to an increase in brain ACh levels. Therefore, the aim of the present work was to compare the anticholinesterase activities of selected phenolic acids singly, and in pairs as well as in combination with selected flavonoids in order to study interactions between these compounds.

\section{MATERIALS AND METHODS}

Reagents. The following reagents were purchased from Sigma-Aldrich (Poznań, Poland): NDGA (74540), RA (536954), 4-hydroxyphenylpyruvic acid (4-OH-PP, 114286), gentisic acid (GA, 149357), homogentisic acid (HGA, H0751), salicylic acid (SA, 84210), homovanillic acid (HVA, H1252), chlorogenic acid (CHA, C3878), caffeic acid (CA, C0625), KAE (60010), PEL (P1659), QUE (Q 125), PHL (P-3449), DEL (43725), CYA (36428), acetylthiocholine iodide (ATChI, 01480), S-butyrylthiocholine chloride (BTCh, B3128), 5,5'-dithiobis-2-nitrobenzoic acid (DTNB, D8130), eserine (E8375), AChE (C3389) and BChE (C7512). MYR (70050) was obtained from Fluka. Other reagents (at least HPLC grade) were purchased from P.O.Ch. (Gliwice, Poland).

Test solutions of phenolic compounds. Solutions of phenolic acids were freshly prepared in a minimal volume of ethanol $(98.0 \%, \mathrm{v} / \mathrm{v})$ followed by dilution to $2 \mathrm{mmol} / \mathrm{L}$ in double deionized (DDI) water. Solutions of flavonoids were freshly prepared in a minimal volume of ethanol $(98.0 \%$, $\mathrm{v} / \mathrm{v}$ ) followed by dilution to the desired concentration using DDI water (PHL $0.64 \mathrm{mmol} / \mathrm{L}, \mathrm{CYA} 0.70 \mathrm{mmol} / \mathrm{L}$, QUE 0.66 $\mathrm{mmol} / \mathrm{L}$, PEL $0.65 \mathrm{mmol} / \mathrm{L}$, DEL $0.66 \mathrm{mmol} / \mathrm{L}$, MYR 0.63 $\mathrm{mmol} / \mathrm{L}, \mathrm{KAE} 0.70 \mathrm{mmol} / \mathrm{L})$. Ethanol content in the test solutions of phenolic acids and flavonoids was below $4 \%$ and $10 \%(\mathrm{v} / \mathrm{v})$, respectively, and had no influence on the enzyme activity (optimization tests not shown).

Inhibition of AChE and BChE. Inhibitory activity was evaluated using a 96-well microplate reader (Tecan Sunrise, Grödig, Austria) based on the method of Ellman et al. [15] with some modifications, as described previously [2]. The absorbance at $405 \mathrm{~nm}$ was read after $30 \mathrm{~min}$ (AChE) or $15 \mathrm{~min}$ (BChE). The false-positive effect was determined according to the method of Rhee et al. [16], with some modifications as previously described [2]. Blank as well as false-positive samples were run in the case of each analysis presented in this study. The inhibitory activity of phenolic compounds was expressed in $\mu \mathrm{M}$ serine, as previously proposed [2, 17]. Dose-response curves were plotted using eleven solutions of eserine in the range of $11.50 \mathrm{mmol} / \mathrm{L}-10.90$ $\mu \mathrm{mol} / \mathrm{L}$. Each sample was analyzed in eight repeats, unless otherwise stated. Statistical differences were calculated using Tukey's test (STATISTICA 8.0, StatSoft, Kraków, Poland) at $\mathrm{p}<0.05$.
Inhibitory activity of single phenolic acids. Each single phenolic acid was tested, as described above, using sixteen solutions in the range of $0.29 \mathrm{mmol} / \mathrm{L}-2.00 \mathrm{mmol} / \mathrm{L}$. A dose-response curve for each phenolic acid was plotted.

Inhibitory activity of combined phenolic acids. Seven phenolic acids (4-OH-PP, CA, CHA, GA, HGA, NDGA, $\mathrm{RA}, 15 \mu \mathrm{L}$ each, $2 \mathrm{mmol} / \mathrm{L}$ ) were combined and mixed with all reagents to determine anticholinesterase activities, as described above. Each sample was analyzed in four repeats.

Inhibitory activity of phenolic acids in pairs. Phenolic acids (4-OH-PP, CA, CHA, GA, HGA, NDGA and RA, 15 $\mu \mathrm{L}$ each, $2 \mathrm{mmol} / \mathrm{L}$ ) were mixed in pairs with all reagents to determine anticholinesterase activities, as described above.

Inhibitory activity of phenolic acids matched with flavonoids. Each phenolic acid (4-OH-PP, CA, CHA, GA, HGA, NDGA or RA: $15 \mu \mathrm{L}, 2 \mathrm{mmol} / \mathrm{L})$ was singly mixed with $15 \mu \mathrm{L}$ of the flavonoid solution (CYA $0.70 \mathrm{mmol} / \mathrm{L}, \mathrm{DEL}$ $0.66 \mathrm{mmol} / \mathrm{L}$, KAE $0.70 \mathrm{mmol} / \mathrm{L}$, MYR $0.63 \mathrm{mmol} / \mathrm{L}$, PEL $0.65 \mathrm{mmol} / \mathrm{L}$, PHL $0.64 \mathrm{mmol} / \mathrm{L}$ or QUE $0.66 \mathrm{mmol} / \mathrm{L})$. Each flavonoid was also tested singly. Anticholinesterase activities were studied as described above.

\section{RESULTS}

Inhibiton of enzymes by single phenolic acids. Phenolic acids were tested in this study for anti-AChE and anti-BChE activity in the range of $0.29 \mathrm{mmol} / \mathrm{L}-2.00 \mathrm{mmol} / \mathrm{L}$. An example of anti-AChE dose-response calibration curve of 4-OH-PP is presented in Figure 1.

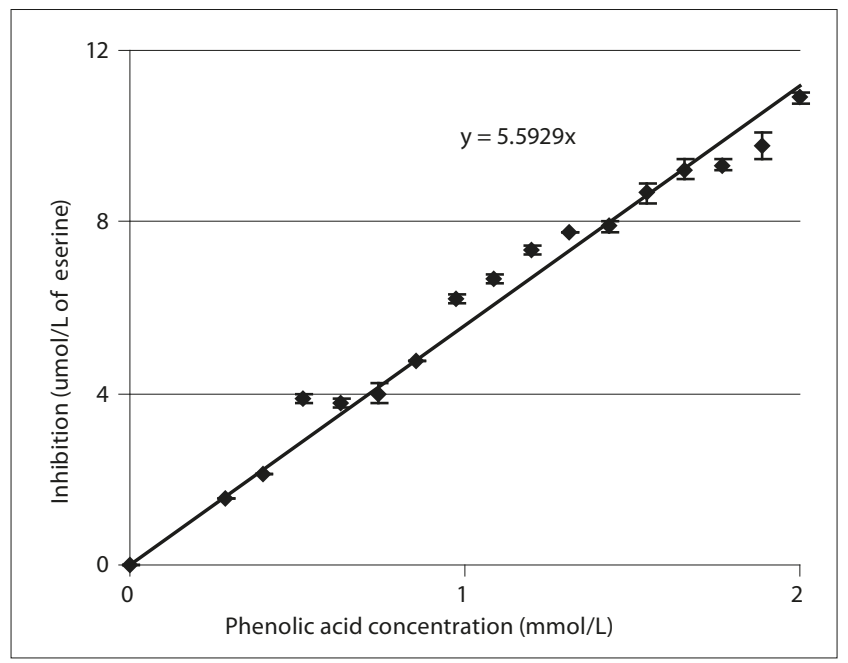

Figure 1. An example anti-AChE dose-response curve of $4-\mathrm{OH}-\mathrm{PP}(\mathrm{n}=8$, mean $\pm S D)$

The false-positive effect arises from the chemical interruption of the reaction between thiocholine and DTNB. This phenomenon is caused by components of complex biological matrices, and not by real inhibition of enzyme activity. A false-positive effect was exerted by CHA, NDGA and RA (Tab. 1). Flavonoids studied in this work exhibited no false-positive effect.

At the concentration of $0.86 \mathrm{mmol} / \mathrm{L}$, the anti-AChE activity of phenolic acids was arranged thus (in decreasing order): $\mathrm{HGA}>4-\mathrm{OH}-\mathrm{PP}>\mathrm{NDGA}>\mathrm{RA}>\mathrm{CA}>\mathrm{GA}=\mathrm{CHA}>$ 
Table 1. The false-positive effect of phenolic acids at $0.29 \mathrm{mmol} / \mathrm{L}-$ $2.00 \mathrm{mmol} / \mathrm{L}$ (means $\pm \mathrm{SEM}, n=8$ )

\begin{tabular}{lcl}
\hline \multirow{2}{*}{ Compound } & \multicolumn{2}{c}{ False-positive effect $(\mu \mathrm{M}$ of eserine) } \\
\cline { 2 - 3 } & \multicolumn{1}{c}{ AChE } & \multicolumn{1}{c}{ BChE } \\
\hline CHA & $0.4 \pm 0.1-3.7 \pm 0.0$ & $0.4 \pm 0.1-0.7 \pm 0.2$ \\
NDGA & $0.1 \pm 0.0-4.3 \pm 0.0$ & $0.4 \pm 0.1-4.4 \pm 0.5$ \\
RA & $0.2 \pm 0.0-0.9 \pm 0.2$ & $0-2.6 \pm 0.4$ \\
\hline
\end{tabular}

HVA > SA (significant as well as non-significant differences, see Table 2). In the case of anti-BChE activity, the order of phenolic acids was (Tab. 3): NDGA $>\mathrm{HGA}>\mathrm{CHA}>4-\mathrm{OH}-$ $\mathrm{PP}>\mathrm{RA}>\mathrm{CA}=\mathrm{GA}>\mathrm{HVA}=\mathrm{SA}$ (significant as well as non-significant differences). HVA and SA, although exerting distinct activities, were the least efficient AChE inhibitors in this study (detailed results not shown) and were excluded from the subsequent parts of the study. For further stages, a phenolic acid concentration of $0.86 \mathrm{mmol} / \mathrm{L}$ was chosen.

Inhibitory activity of combined phenolic acids. The antiAChE activity of all phenolic acids calculated from doseresponse curves as the sum of the inhibitory activities of individual compounds was $20.8 \pm 1.8 \mu \mathrm{mol} / \mathrm{L}$ of eserine. However, the measured inhibitory activity was significantly $(\mathrm{p}<0.05)$ lower and amounted to only $2.9 \pm 0.2 \mu \mathrm{mol} / \mathrm{L}$ of eserine. Similarly, the sum of anti-BChE activities of all phenolic acids singly was $16.9 \pm 1.5 \mu \mathrm{mol} / \mathrm{L}$ of eserine and it was significantly $(\mathrm{p}<0.05)$ higher than the detected activity of the mixture of all phenolic acids $(5.7 \pm 0.4 \mu \mathrm{mol} / \mathrm{L}$ of eserine $)$.

Inhibitory activity of phenolic acids in pairs. The anti-AChE (Tab. 2) and anti-BChE activity (Tab. 3) of phenolic acids in pairs, each compound at $0.86 \mathrm{mmol} / \mathrm{L}$, was, in most cases, lower than the sum of activities presented by two phenolic acids in separate solutions, although at a significance level of $\mathrm{p}>0.05$. Only in the case of a few pairs (AChE: HGA + CHA, $\mathrm{HGA}+\mathrm{GA}$; BChE: NDGA + 4-OH-PP, NDGA + CA, NDGA $+\mathrm{CHA}, \mathrm{NDGA}+\mathrm{GA}, \mathrm{NDGA}+\mathrm{RA}$ ) was the inhibitory activity significantly $(\mathrm{p}<0.05)$ lower than the sum of the activities presented by phenolic acids singly in solutions. Also, in the case of a few samples (AChE: GA + CHA, RA + CA, RA + CHA; BChE: GA + CA), the inhibitory activity of the solution containing two phenolic acids was equal to or higher than the sum of inhibitions exerted by the same two acids tested singly, although at a significance level of $\mathrm{p}>0.05$ (Tab. 2, 3).

Inhibitory activity of phenolic acids matched with flavonoids. The anti-AChE and anti-BChE activity of phenolic acids coupled with flavonoids (Tab. 4, 5), in most cases, was lower than the sum of activities of single compounds present in the solution, although at a significance level of $p>0.05$. Only in the case of two pairs (AChE: PHL + 4-OH-PP; BChE: PHL + NDGA) was the inhibitory activity significantly $(\mathrm{p}<0.05)$ lower than the sum of the activities presented by phenolic compounds singly in solutions. In selected samples (AChE: MYR + GA, KAE + GA, PEL + CHA, PEL + GA; BChE: $\mathrm{KAE}+\mathrm{HGA}, \mathrm{KAE}+\mathrm{GA}$ ), the inhibitory activity of the solution containing two phenolic compounds was higher than the sum of inhibitions exerted by the same compounds tested singly, although at a significance level of $\mathrm{p}>0.05$ (Tab. 4, 5).Finally, in the case of the pairs MYR + RA (AChE) and $\mathrm{KAE}+4-\mathrm{OH}-\mathrm{PP}$ (BChE), the inhibitory activity was significantly $(\mathrm{p}<0.05)$ higher than the sum of the activities presented by phenolic compounds singly in solutions.

Table 2. The anti-AChE activity of phenolic acids in pairs ( $\mu \mathrm{mol} / \mathrm{L}$ of eserine, $\mathrm{n}=8, \mathrm{mean} \pm \mathrm{SD}$ ), each compound at $0.86 \mathrm{mmol} / \mathrm{L}$

\begin{tabular}{|c|c|c|c|c|c|c|c|}
\hline \multicolumn{2}{|c|}{ Compound } & $\begin{array}{c}C A \\
0.9 \pm 0.0^{\mathrm{ab}}\end{array}$ & $\begin{array}{c}\text { CHA } \\
0.4 \pm 0.1^{\mathrm{a}}\end{array}$ & $\begin{array}{c}\mathrm{GA} \\
0.5 \pm 0.1^{\mathrm{ab}}\end{array}$ & $\begin{array}{c}\text { HGA } \\
10.8 \pm 0.2^{i}\end{array}$ & $\begin{array}{c}\text { NDGA } \\
1.9 \pm 0.1^{\mathrm{abcd}}\end{array}$ & $\begin{array}{c}\text { RA } \\
1.5 \pm 0.2^{\text {abc }}\end{array}$ \\
\hline 4-OH-PP & $4.8 \pm 0.2^{\mathrm{efg}}$ & $5.3 \pm 0.2^{\mathrm{fg} t}$ & $4.5 \pm 0.2^{\mathrm{eft}}$ & $3.6 \pm 0.0^{\text {deft }}$ & $6.7 \pm 1.1^{\mathrm{ght}}$ & $3.8 \pm 0.1^{\text {deft }}$ & $1.9 \pm 0.1^{\mathrm{abcdt}}$ \\
\hline $\mathrm{CHA}$ & $0.4 \pm 0.1^{\mathrm{a}}$ & & - & $1.0 \pm 0.1^{\mathrm{ab} \vartheta}$ & $5.3 \pm 0.2^{\mathrm{fg}^{*}}$ & $2.4 \pm 0.5^{\mathrm{bcd} t}$ & $2.0 \pm 0.2^{\text {abcdo }}$ \\
\hline $\mathrm{GA}$ & $0.5 \pm 0.1^{\mathrm{ab}}$ & & & - & $7.6 \pm 1.0^{h^{*}}$ & $2.1 \pm 0.1^{\text {abcdt }}$ & $1.9 \pm 0.0^{\mathrm{abcdt}}$ \\
\hline $\mathrm{HGA}$ & $10.8 \pm 0.2^{i}$ & & & & - & $9.8 \pm 0.1^{\text {it }}$ & $11.6 \pm 0.3^{i+}$ \\
\hline NDGA & $1.9 \pm 0.1^{\mathrm{cd}}$ & & & & & - & $3.3 \pm 0.2^{\text {cdet }}$ \\
\hline
\end{tabular}

* inhibitory activity lower than expected $(p<0.05)$

inhibitory activity lower than expected $(p>0.05)$

${ }^{\circ}$ inhibitory activity equal to the expected value or higher than expected value $(p>0.05)$

Table 3. The anti-BChE activity of phenolic acids in pairs ( $\mu$ mol/L of eserine, $\mathrm{n}=8, \mathrm{mean} \pm \mathrm{SD}$ ), each compound at $0.86 \mathrm{mmol} / \mathrm{L}$

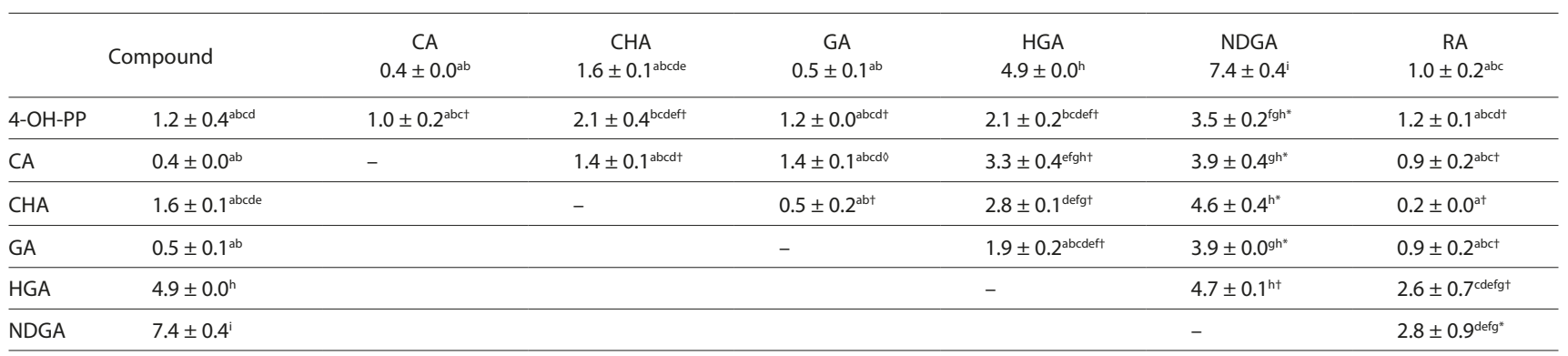


Table 4. The anti-AChE activity of phenolic acids combined with flavonoids ( $\mu \mathrm{mol} / \mathrm{L}$ of eserine, $\mathrm{n}=8, \mathrm{mean} \pm \mathrm{SD}$ ). Phenolic acid concentration 0.86 $\mathrm{mmol} / \mathrm{L}$, for flavonoid concentrations, see Methods section

\begin{tabular}{|c|c|c|c|c|c|c|c|c|}
\hline \multicolumn{2}{|c|}{ Compound } & $\begin{array}{c}\text { CYA } \\
0.7 \pm 0.0^{\text {abcde }}\end{array}$ & $\begin{array}{c}\text { DEL } \\
0.4 \pm 0.0^{\mathrm{ab}}\end{array}$ & $\begin{array}{c}\text { MYR } \\
1.4 \pm 0.1^{a-h}\end{array}$ & $\begin{array}{c}\text { KAE } \\
0.9 \pm 0.2^{\mathrm{a}-\mathrm{g}}\end{array}$ & $\begin{array}{c}\text { PEL } \\
0.9 \pm 0.1^{\mathrm{a}-\mathrm{g}}\end{array}$ & $\begin{array}{c}\text { PHL } \\
1.9 \pm 0.0^{c-i}\end{array}$ & $\begin{array}{c}\text { QUE } \\
0.9 \pm 0.2^{\mathrm{a}-\mathrm{g}}\end{array}$ \\
\hline 4-OH-PP & $4.8 \pm 0.2^{\mathrm{Im}}$ & $4.9 \pm 0.2^{\mathrm{Imt}}$ & $4.4 \pm 0.2^{\mathrm{klm} \dagger}$ & $4.8 \pm 0.0^{\mathrm{Imt}}$ & $5.4 \pm 0.7^{\mathrm{m \dagger}}$ & $5.1 \pm 0.1^{\mathrm{Imt}}$ & $3.8 \pm 0.2^{\left.\mathrm{jk}\right|^{*}}$ & $4.9 \pm 0.1^{\mathrm{Imt}}$ \\
\hline$C A$ & $0.9 \pm 0.0^{\mathrm{a}-\mathrm{g}}$ & $1.0 \pm 0.0^{\mathrm{a}-\mathrm{g} t}$ & $0.3 \pm 0.1^{\text {a† }}$ & $1.4 \pm 0.2^{\mathrm{a}-\mathrm{ht}}$ & $1.2 \pm 0.0^{\mathrm{a}-\mathrm{g} \dagger}$ & $0.9 \pm 0.1^{\mathrm{a}-\mathrm{g} t}$ & $0.3 \pm 0.1^{\text {a }}$ & $0.7 \pm 0.1^{\text {aet }}$ \\
\hline $\mathrm{CHA}$ & $0.4 \pm 0.1^{\mathrm{ab}}$ & $0.3 \pm 0.1^{\text {at }}$ & $0.6 \pm 0.2^{\mathrm{abcd} t}$ & $1.7 \pm 0.2^{\mathrm{a}-\mathrm{i \dagger}}$ & $1.3 \pm 0.4^{\mathrm{a}-9 t}$ & $1.9 \pm 0.1^{\text {cio }}$ & $0.3 \pm 0.1^{\text {a }}$ & $0.8 \pm 0.1^{\mathrm{a}-\mathrm{ft}}$ \\
\hline GA & $0.5 \pm 0.1^{\mathrm{abc}}$ & $0.7 \pm 0.0^{\mathrm{a}-\mathrm{e}}$ & $0.3 \pm 0.2^{\mathrm{a} \dagger}$ & $2.1 \pm 0.1^{\mathrm{e}-\mathrm{i} \theta}$ & $1.8 \pm 0.5^{b-18}$ & $1.9 \pm 0.1^{c-1 i}$ & $0.4 \pm 0.0^{\mathrm{abt}}$ & $0.9 \pm 0.1^{\mathrm{a}-\mathrm{g} \dagger}$ \\
\hline $\mathrm{HGA}$ & $10.8 \pm 0.4^{\circ}$ & $9.6 \pm 0.3^{\text {not }}$ & $10.2 \pm 0.2^{\text {not }}$ & $9.0 \pm 0.1^{\text {nt }}$ & $10.1 \pm 0.2^{\text {not }}$ & $10.4 \pm 0.4^{\text {not }}$ & $9.9 \pm 0.1^{\text {not }}$ & $10.7 \pm 0.1^{\text {o† }}$ \\
\hline NDGA & $1.9 \pm 0.1^{c-i}$ & $1.6 \pm 0.2^{\mathrm{a}-\mathrm{it}}$ & $1.4 \pm 0.1^{\mathrm{a}-\mathrm{ht}}$ & $2.0 \pm 0.1^{d-i \dagger}$ & $2.2 \pm 0.3^{\mathrm{fi} i t}$ & $1.4 \pm 0.7^{\mathrm{a}-\mathrm{ht}}$ & $2.8 \pm 0.2^{\mathrm{hijt}}$ & $2.8 \pm 0.1^{\mathrm{hijt}}$ \\
\hline $\mathrm{RA}$ & $1.5 \pm 0.2^{\mathrm{a}-\mathrm{h}}$ & $1.1 \pm 0.3^{\mathrm{a}-\mathrm{gt}}$ & $1.1 \pm 0.2^{\mathrm{a}-\mathrm{gt}}$ & $3.0 \pm 0.2^{\mathrm{j} \mathrm{j} \ell}$ & $2.2 \pm 0.6^{\text {fghit }}$ & $1.2 \pm 0.1^{\mathrm{a}-\mathrm{g} t}$ & $0.4 \pm 0.2^{\mathrm{abt}}$ & $2.3 \pm 0.2^{\text {ghit }}$ \\
\hline
\end{tabular}

* inhibitory activity lower than expected $(\mathrm{p}<0.05)$

${ }^{+}$inhibitory activity lower than expected ( $\left.p>0.05\right)$

inhibitory activity higher than expected $(p>0.05$ or $p<0.05)$

Table 5. The anti-BChE activity of phenolic acids combined with flavonoids ( $\mu \mathrm{mol} / \mathrm{L}$ of eserine, $\mathrm{n}=8, \mathrm{mean} \pm \mathrm{SD}$ ). (Phenolic acid concentration $0.86 \mathrm{mmol} / \mathrm{L}$, for flavonoid concentrations, see Methods section)

\begin{tabular}{|c|c|c|c|c|c|c|c|c|}
\hline \multicolumn{2}{|c|}{ Compound } & $\begin{array}{c}\text { CYA } \\
1.4 \pm 0.2^{\mathrm{a}-\mathrm{g}}\end{array}$ & $\begin{array}{c}\text { DEL } \\
1.4 \pm 0.1^{\mathrm{a}-\mathrm{g}}\end{array}$ & $\begin{array}{c}\text { MYR } \\
0.4 \pm 0.0^{\mathrm{ab}}\end{array}$ & $\begin{array}{c}\text { KAE } \\
0.7 \pm 0.1^{\mathrm{a}-\mathrm{d}}\end{array}$ & $\begin{array}{c}\text { PEL } \\
1.8 \pm 0.0^{c-i}\end{array}$ & $\begin{array}{c}\text { PHL } \\
1.6 \pm 0.1^{b-h}\end{array}$ & $\begin{array}{c}\text { QUE } \\
1.9 \pm 0.1^{\mathrm{d}-\mathrm{i}}\end{array}$ \\
\hline 4-OH-PP & $1.2 \pm 0.4^{\mathrm{a}-\mathrm{f}}$ & $1.8 \pm 0.4^{\text {cit }}$ & $1.0 \pm 0.1^{\mathrm{a}-\mathrm{ft}}$ & $1.0 \pm 0.2^{\mathrm{a}-\mathrm{ft}}$ & $3.0 \pm 0.0^{\mathrm{ijk} \diamond}$ & $2.6 \pm 0.2^{\text {ghijt }}$ & $0.9 \pm 0.2^{\mathrm{a}-\mathrm{et}}$ & $2.8 \pm 0.4^{\mathrm{hijkt}}$ \\
\hline $\mathrm{CHA}$ & $1.6 \pm 0.1^{\mathrm{b}-\mathrm{h}}$ & $1.9 \pm 0.2^{\mathrm{d}-\mathrm{it}}$ & $2.3 \pm 0.2^{\text {fghit }}$ & $0.4 \pm 0.0^{\mathrm{ab} t}$ & $0.5 \pm 0.2^{\mathrm{abct}}$ & $1.8 \pm 0.1^{c-i t}$ & $0.7 \pm 0.1^{\mathrm{a}-\mathrm{d} t}$ & $1.1 \pm 0.1^{\mathrm{a}-\mathrm{ft}}$ \\
\hline GA & $0.5 \pm 0.2^{\mathrm{abc}}$ & $1.6 \pm 0.2^{\mathrm{b}-\mathrm{ht}}$ & $1.8 \pm 0.4^{\mathrm{cht} t}$ & $0.2 \pm 0.1^{\text {a }}$ & $1.4 \pm 0.1^{\mathrm{a}-\mathrm{g} 0}$ & $1.6 \pm 0.5^{\mathrm{b}-\mathrm{h} t}$ & $1.4 \pm 0.2^{\mathrm{a}-\mathrm{g} t}$ & $2.1 \pm 0.4^{\mathrm{e}-\mathrm{i} \dagger}$ \\
\hline HGA & $4.9 \pm 0.0^{1 \mathrm{~m}}$ & $4.0 \pm 0.4^{\mathrm{klt}}$ & $4.6 \pm 0.2^{1+}$ & $3.7 \pm 0.4^{\mathrm{klt}}$ & $6.0 \pm 0.2^{\mathrm{mn} \theta}$ & $6.0 \pm 0.1^{\mathrm{mnt}}$ & $4.6 \pm 0.2^{1+}$ & $4.6 \pm 0.0^{1 t}$ \\
\hline NDGA & $7.4 \pm 0.4^{\circ}$ & $7.0 \pm 0.2^{\text {not }}$ & $6.9 \pm 0.1^{\text {not }}$ & $6.2 \pm 0.2^{\mathrm{mno \dagger}}$ & $7.4 \pm 0.5^{\circ \dagger}$ & $6.7 \pm 0.2^{\text {not }}$ & $4.9 \pm 0.1^{1 \mathrm{~m}^{*}}$ & $7.4 \pm 0.1^{\text {o† }}$ \\
\hline RA & $1.1 \pm 0.4^{\mathrm{a}-\mathrm{f}}$ & $0.5 \pm 0.1^{\mathrm{abct}}$ & $0.7 \pm 0.1^{\mathrm{a}-\mathrm{d} t}$ & $0.9 \pm 0.2^{\mathrm{a}^{\mathrm{e} t}}$ & $1.4 \pm 0.0^{\mathrm{a}-\mathrm{g} \dagger}$ & $1.4 \pm 0.0^{\mathrm{a}-\mathrm{gt}}$ & $1.4 \pm 0.2^{\mathrm{a}-\mathrm{g} t}$ & $1.4 \pm 0.1^{\mathrm{a}-\mathrm{g} t}$ \\
\hline
\end{tabular}

* inhibitory activity lower than expected $(p<0.05)$

${ }^{+}$inhibitory activity lower than expected $(p>0.05)$

${ }^{0}$ inhibitory activity higher than expected $(p>0.05$ or $p<0.05)$

\section{DISCUSSION}

In the presented study, an attempt was made to study the interactions between cholinesterases and their inhibitorsphenolic acids and flavonoids. Phenolic compounds were chosen for testing, based on previous studies $[2,6,18]$. The results obtained in the current study confirm the in vitro anticholinesterase activity of these compounds. AChE and BChE share many structural similarities (50 - 55\% speciesdependent sequence similarity), and the active site of BChE (Ser198, His438 and Glu325) and oxyanion hole (Gly116, Gly117 and Ala199) are identical to those of AChE. However, differences in the inhibitory activity caused by individual phenolic compounds (Tab. 2-5) probably originate from some minor differences in the structures of both enzymes; for example, the active site of AChE is formed by fourteen aromatic amino acid residues, whereas in $\mathrm{BChE}$, six or eight of them are replaced with aliphatic residues, depending on the origin of the enzyme [19]. Detailed comparisons of AChE and $\mathrm{BChE}$ have been presented in numerous review papers [20].

Phenolic compounds were efficient cholinesterase inhibitors singly in the solution, but combined phenolic acids, as well as phenolic acids coupled with flavonoids, were less efficient inhibitors than could have been expected (calculated) from the sum of activities exerted by both compounds. It should be strongly underlined that the lower activity of pairs of phenolic compounds in comparison to single compounds (Tab. 2-5) was not confirmed statistically in the case of most of the tested pairs (insignificant differences, $\mathrm{p}>0.05$ ). Nevertheless, an explanation of this phenomenon could be sought in an analysis of the affinity of inhibitors to the enzyme molecules. The active site of AChE and BChE can be divided into several subsites: omega loop (Cys69 - Cys96), peripheral anionic subsite (Asp74, Tyr124, Ser125, Trp286, Tyr337, Tyr341), anionic subsite (Trp86, Tyr133, Glu202, Gly448, Ile451), oxyanion hole (Gly121, Gly122, Ala204), catalytic triad (Ser203, His447, Glu334), and acyl binding pocket (Trp236, Phe295, Phe297, Phe338) [21]. It is most likely that the phenolic acids and flavonoids studied in this work were simultaneously docking in different locations in the enzyme molecule, doubling the action of each inhibitor. Thus, the total inhibitory effect was lower than that expected from the results involving both phenolic compounds tested singly. Three-dimensional pharmacophore conformations of binding sites in AChE and BChE are essential for the non-covalent interaction of the enzyme with inhibitors, but the number of studies concerning the docking of phenolic compounds with $\mathrm{AChE}$ or $\mathrm{BChE}$ is limited. Therefore, the synergy/antagonism issues between individual phenolic compounds are, as yet, poorly elucidated. A synergistic effect of two inhibitors on a single target protein is possible in the case of two independent binding sites (e.g. active site and allosteric site), or if the active site is large enough to accommodate both inhibitors adjacent to one another.

It is known that $\mathrm{AChE}$ (BChE) may have various binding sites for ligands. QUE docked by hydroxyl groups in positions 5 and 7 in ring B to Tyr332, Trp430, Gly78, Tyr440, Trp82 and Ser198 [22]. In another study, QUE bound by several hydrogen bonds in the anionic subsite of AChE: O3 and O5 bound with the $\mathrm{OH}$ group of Tyr133 and $\mathrm{O} 4$ with the oxygen atom of Trp86. Moreover, the entire QUE molecule showed hydrophobic interactions with Ser125, His447 and Glu202 
in the anionic subsite of AChE. The oxygen atoms of the phenyl side chain of QUE showed hydrogen bonding to the peripheral anionic subsite (O6 from QUE with O and OE1 atoms of the Tyr72 and Gln71, respectively, and $\mathrm{O} 7$ with the $\mathrm{N}$ atom of Asp74). QUE effectively bound to BChE by at least five hydrogen bonds: atoms $\mathrm{O} 3$ and $\mathrm{O} 5$ with atom $\mathrm{OH}$ of Tyr128 and atom O4 with the OG1 atom of Thr120, and atom O6 showed hydrogen bonds with the OD1 and N atoms of Asn83 and Asp70, respectively [23]. Alkenyl phenol and salicylic acid derivatives (+)-2-hydroxy-6-(10'hydroxypentadec-8'(E-enyl) benzoic acid, 2-hydroxy-6-(pentadec-10'(Z)-enyl)benzoic acid and 2-hydroxy-6-(10'(Z)-heptadecenyl)benzoic acid isolated from Knema laurina were effective inhibitors of AChE. All compounds were efficient AChE inhibitors due to the hydroxyl group binding to the carbonyl oxygen of Gly117 (hydrogen bonding). This, in turn, improved the positioning of the phenyl ring to involve a $\pi-\pi$ stacking interaction with Trp84. The hydroxyl group in 2-hydroxy6 -(10'(Z)-heptadecenyl)benzoic acid was also involved in a short contact with Tyr130 [24]. Docking studies revealed that epigallocatechin gallate strongly bound to AChE via several hydrogen bonds to amino acids Glu202, Asn87, Asp74, Tyr124, His447, Tyr133 and Tyr337 [25].

There is the possibility that some phenolic compounds may act as AChE (BChE) activators. Srividhya et al. [25] observed the activation of AChE by epigallocatechingallate in in silico and docking studies, as well as in in vivo studies involving Wistar rats. Caffeic acid was shown to increase AChE activity in the cerebral cortex, cerebellum, hypothalamus, whole blood, and also lymphocytes in the case of in vitro studies involving rats [26]. Moreover, caffeic acid increased AChE activity in vivo after co-administration with malathion to rats. The authors speculated that caffeic acid (or its derivate(s)) could lead to the activation of the catalytic site of AChE within the second site interaction [27].

\section{CONCLUSIONS}

It can be stated that selected phenolic acids and flavonoids exhibit useful inhibitory activity towards AChE and BChE in model solutions. However, the results obtained in the presented study concerning synergism/no interaction between phenolic compounds, were not unequivocal. Therefore, as a next step, studies on the anticholinesterase activity of complex solutions (biological matrices), including docking studies, should be performed, as well as studies involving a wider range of phenolic compounds.

\section{Acknowledgement}

The study was supported by the Polish Ministry of Science and Higher Education in Warsaw, Poland, under Scientific Grant No. 2339/B/P01/2010/38.

\section{REFERENCES}

1. Yabe T, Hirahara H, Harada N, Ito N, Nagai T, Sanagi T, et al. Ferulic acid induces neural progenitor cell proliferation in vitro and in vivo. Neuroscience 2010; 165: 515-524.

2. Szwajgier D, Borowiec K. Phenolic acids from malt are efficient acetylcholinesterase and butyrylcholinesterase inhibitors. J Inst Brew. 2012a; 118: 40-48.
3. Karakida F, Ikeya Y, Tsunakawa M, Yamaguchi T, Ikarashi Y, Takeda $\mathrm{S}$, et al. Cerebral protective and cognition-improving effects of sinapic acid in rodents. Biol Pharm Bull. 2007; 30: 514-519.

4. Hamaguchi T, Ono K, Murase A, Yamada M. Phenolic compounds prevent Alzheimer's pathology through different effects on the amyloid- $\beta$ aggregation pathway. Am J Pathol. 2009; 175: 2557-2565.

5. Ishge K, Schubert D, Sagara Y. Flavonoids protect neuronal cells from oxidative stress by three distinct mechanisms. Free Rad Bio Med. 2001; 30: 433-446.

6. Szwajgier D. Anticholinesterase activities of selected polyphenols. Pol J Food Nutr Sci. 2014; 64, doi: 102478/v10222-012-0089-x.

7. Ono K, Yoshiike Y, Takashima A, Hasegawa K, Naiki H, Yamada M. Potent anti-amyloidogenic and fibril-destabilizing effects of polyphenols in vitro: implications for the prevention and therapeutics of Alzheimer's disease. J Neurochem. 2003; 87: 172-181.

8. Porat Y, Abramowitz A, Gazit E. Inhibition of amyloid fibril formation by polyphenols: structural similarity and aromatic interactions as a common inhibition mechanism. Chem Biol Drug Des. 2006; 67: 27-37.

9. Isoda $\mathrm{H}$, Talorete TPN, Kimura M, Maekawa $\mathrm{T}$, Inamori $\mathrm{Y}$, Nakajima N, et al. Phytoestrogens genistein and daidzin enhance the acetylcholinesterase activity of the rat pheochromocytoma cell line PC12 by binding to the estrogen receptor. Cytotechnology 2002; 40: 117-123.

10. Young J, Wahle KWJ, Boyle SP. Cytoprotective effects of phenolic antioxidants and essential fatty acids in human blood monocyte and neuroblastoma cell lines: Surrogates for neurological damage in vivo. Prostag Leukotr Ess. 2008; 78: 45-59.

11. Choi Y-T, Jung C-H, Lee S-R, Bae J-H, Baek W-K, Suh M-H, et al. The green tea polyphenol (-)-epigallocatechingallate attenuates $\beta$-amyloidinduced neurotixicity in cultured hippocampal neurons. Life Sci. 2001; 70: 603-614.

12. Schroeter H, Williams RJ, Matin R, Iversen L, Rice-Evans CA. Phenolic antioxidants attenuate neuronal cell death following uptake of oxidized low-density lipoprotein. Free Rad Bio Med. 2000; 12: 1222-1233.

13. Whitehouse PJ, Price DL, Clark AW, Coyle JT, DeLong MR. Alzheimer's disease: evidence for selective loss of cholinergic neurons in the nucleus basalis. Ann Neurol. 1981; 10: 115-126.

14. Rao AA, Sridhar GR, Das UN. Elevated butyrylcholinesterase and acetylcholinesterase may predict the development of type 2 diabetes mellitus and Alzheimer's disease. Med Hyphoteses. 2007; 69: 1272-1276.

15. Ellman G L, Lourtney D K, Andres V, Gmelin G. A new and rapid colorimetric determination of acetylcholinesterase activity. Biochem Pharmacol. 1961; 7: 88-95.

16. Rhee IK, van Rijn RM, Verpoorte R. Qualitative determination of false-positive effects in the acetylcholinesterase assay using thin layer chromatography. Phytochem Analysis. 2003; 14: 127-131.

17. Szwajgier D, Borowiec K. Screening for cholinesterase inhibitors in selected fruits and vegetables. EJPAU 2012b; 15, \#06, available online: http://www.ejpau.media.pl/articles/volume15/issue2/art-06.pdf (access: November 2015).

18. Szwajgier D. Anticholinesterase activity of phenolic acids and their derivatives. Z Naturforsch. 2013; 68c: 125-132.

19. Nachon F, Masson P, Nicolet Y, Lockridge O, Fontecilla-Camps JC. Comparison of structures of butyrylcholinesterase and acetylcholinesterase. In: Giacobini E. (Editor): Butyrylcholinesterase, its function and inhibitors, Martin Dunitz Ltd., London, 2003.p.39-54.

20. Johnson G, Moore SW. Why has butyrylcholinesterase been retained? Structural and functional diversification in a duplicated gene. Neurochem Int. 2012; 61: 783-797.

21. Wiesner J, Kriz Z, Kuca K, Jun D, Koca J. Acetylcholinesterases - the structural similarities and differences. J Enzyme Inhib Med Chem. 2007; 22: 417-424.

22. Ji H-F, Zhang H-Y. Theoretical evaluation of flavonoids as multipotent agents to combat Alzheimer's disease. J Mol Struct. (Theochem) 2006; 767: 3-9.

23. Khan MTH, Orhan I, Senol FS, Kartal M, Sener B, Dvorská M, et al. Cholinesterase inhibitory activities of some flavonoid derivatives and chosen xantone and their molecular docking studies. Chem Biol Interact. 2009; 181: 383-389.

24. Akhtar MN, Lam KW, Abas F, Maulidiani, Ahmad S, Shah SAA, et al. New class of acetylcholinesterase inhibitors from the stem bark of Knema laurina and their structural insights. Bioorg \& Med Chem Lett. 2011; 21: 4097-4103.

25. Srividhya R, Gayathri R, Kalaiselvi P. Impact of epigallo catechin-3gallate on acetylcholine-acetylcholine esterase cycle in aged rat brain. Neurochem Int. 2012; 60: 517-522.

26. Anwar J, Spanevello M, Thomé G, Stefanello N, Schmatz R, Gutierres J, et al. Effects of caffeic acid on behavioral parameters and on the activity of acetylcholinesterase in different tissues from adult rats. Pharmacol Biochem Behav. 2012; 103: 386-394.

27. Rezg R, Mornagui B, El-Fazaa S, Gharbi N. Caffeic acid attenuates malathion induced metabolic disruption in rat liver, involvement of acetylcholinesterase activity. Toxicology 2008; 250: 27-31. 